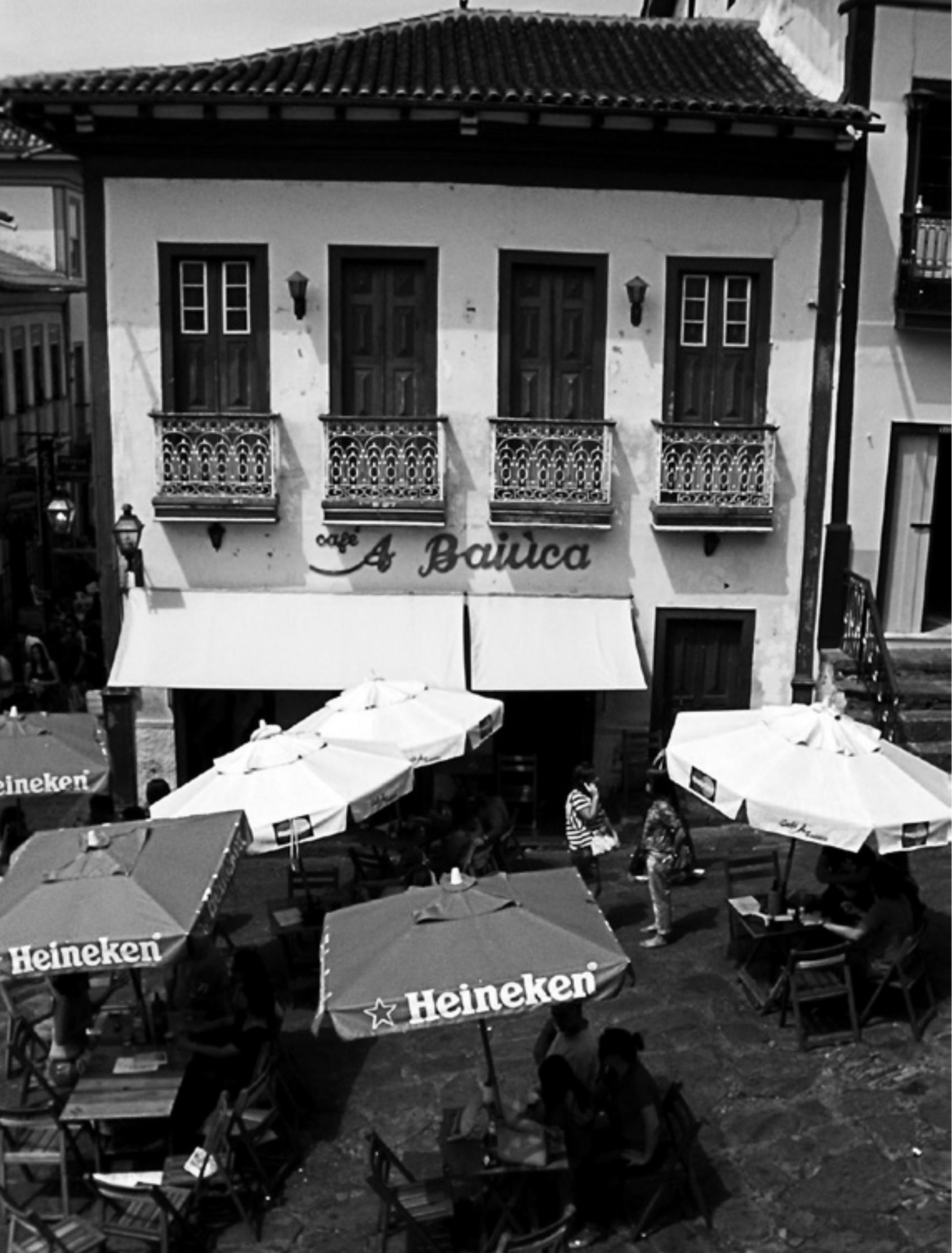




\title{
Cooperação e Sustentabilidade no Setor Turístico: estudo sobre Micro e Pequenas Empresas de Cavalcante (GO, Brasil)
}

Cooperation, Competitiveness and Sustainability in the tourism sector: a study about micro and small enterprises in Cavalcante (Goiás, Brazil)

\author{
Nathália Garay ${ }^{1}$ \\ Leandro Santana ${ }^{2}$ \\ Helena Costa ${ }^{3}$
}

1 Mestranda em Turismo, Bacharel em Administração. Email: nathgaray@hotmail.com

2 Professor Colaborador da Universidade de Brasília (UnB), Mestre em Estratégia e Inovação organizacional e Bacharel em Administração. Assessor da Universidade Corporativa Banco do Brasil (UniBB).

Email: santana.leandro2@gmail.com

3 Professora Adjunta III da Universidade de Brasília. Doutora em Desenvolvimento Sustentável, Mestre em Turismo e Hotelaria, Bacharel em Administração. Coordenadora do LETS UnB (Laboratório de Estudos de Turismo e Sustentabilidade. Email: helenacosta@unb.br 


\title{
Resumo
}

A cooperação entre organizações do turismo a fim de atingir objetivos comuns pode trazer benefícios e vantagem competitiva aos envolvidos, especialmente quando se tratam de micro e pequenas empresas (MPE). Assim, o objetivo do estudo consistiu em verificar as relações de cooperação e possíveis vantagens para os empreendimentos turísticos e para a cidade de Cavalcante/GO, no que diz respeito à competitividade dos negócios e da sustentabilidade do destino. Para tanto, realizou-se uma pesquisa com abordagem qualitativa com utilização de um roteiro de entrevista semiestruturado junto a 21 empresas ligadas ao turismo em Cavalcante/GO. Os dados foram analisados conforme a técnica de análise de conteúdo e revelaram que o próprio turismo, as estruturas da cidade e as relações cooperativas são incipientes. Na ótica dos entrevistados, a ausência de suporte público e a falta de interesse dos envolvidos são os dois principais fatores que dificultam a criação e o funcionamento das redes de cooperação. De forma geral, verificou-se uma inclinação positiva dos representantes para cooperarem, mas que pouco se reflete em ações concretas no dia a dia. Por isso, não foi possível relacionar a cooperação diretamente com a competitividade e com o desenvolvimento sustentável das empresas e da região como um todo.

Palavras Chave: Desenvolvimento local sustentável. MPE. Redes. Cooperação. Turismo.

\begin{abstract}
Cooperation between tourist organizations in order to achieve common goals can bring benefits and competitive advantage to those involved, especially when dealing with micro and small enterprises (MSEs). The objective of the study was to examine relationships of cooperation and possible benefits for tourism developments and the city of Cavalcante / GO, with regard to the competitiveness of business and the destination sustainability. To this end, we carried out a research with qualitative approach which applied a semi-structured interview guide with 21 tourist companies Cavalcante / GO. Data were analyzed according to the technique of content analysis. The results revealed that tourism itself, city structures and cooperative relations are incipient. In the view of respondents, the lack of public support and the lack of interest of those involved are the two main factors that hinder the establishment and operation of cooperation networks. Overall, there was a positive slope of the representatives to cooperate, but that is not reflected in concrete action on a daily basis. So it was not possible to relate the cooperation directly with the competitiveness and sustainable development of enterprises and the region as a whole.
\end{abstract}

Keywords: Sustainable local development. MPE. Networks. Cooperation.

Tourism. 


\section{INTRODUÇÃO}

As empresas estão inseridas num ambiente bastante dinâmico, caracterizado por mudanças sociais, econômicas, culturais e políticas cada vez mais rápidas, além da atual preocupação com a preservação ambiental e desenvolvimento sustentável, que também estão influenciando as mudanças organizacionais (SOUZA; CÂNDIDO, 2009). Essas questões têm levantado estudos relacionados à competitividade e a novas estratégias sustentáveis empresariais voltadas não só para a própria empresa como também para as localidades em que estão inseridas.

O estabelecimento de redes de cooperação é uma solução que tem sido cada vez mais abordada na literatura e adotada nas organizações, solução essa que difere das estratégias tradicionais, pois visa reunir atributos que permitam uma adequação ao ambiente competitivo em uma única estrutura, sustentada por ações uniformizadas, porém descentralizadas, que viabilizem ganhos competitivos pelas empresas associadas, trazendo consigo o fortalecimento recíproco dos participantes. Assim, é uma conexão entre empresas com vistas às relações estruturadas, social e economicamente, no sentido de atender objetivos individuais e coletivos (HÅKANSSON; SNEHOTA, 1989).

Na literatura o tema da cooperação tem sido muito apontado como fonte de competitividade ou vantagem competitiva. Esse artigo visa, então, mencionar as vertentes dessa vantagem aliadas ao desenvolvimento sustentável local que a cooperação tem trazido potencialmente às regiões, principalmente destinações turísticas com áreas naturais. Segundo Denicolai, Cioccarelli e Zucchella (2010), o estudo da cooperação como recurso estratégico de destinos turísticos é muito apropriado, uma vez que o sistema turístico de uma região, com frequência, é formado por diversos agentes autônomos que guardam forte interdependência entre si, e por turistas que, habitualmente, enxergam o valor gerado por um destino como sendo um sistema único. Afinal, parte-se da premissa de Ritchie e Crouch (2007) de que competitividade e sustentabilidade dos destinos turísticos são inseparáveis.

Assim, procurando entender melhor o estabelecimento de redes de cooperação no setor turístico e como essas relações podem impactar a comunidade local, o artigo tem como objetivo verificar a existência de cooperação entre as organizações de Cavalcante (GO) e suas contribuições para a competitividade e sustentabilidade do destino turístico. Para tanto, o artigo está organizado em 3 partes: referencial teórico, que discute o conceito de redes de cooperação entre MPE atrelado às noções de competitividade e sustentabilidade; os métodos da pesquisa e os resultados, seguidos por suas considerações finais. 


\section{COOPERAÇÃO ENTRE MPE NO TURISMO, COMPETITIVIDADE E SUSTENTABILIDADE}

O setor turístico é diretamente ligado à utilização de espaço físico, isto é, a região em que está inserido. A literatura aponta que o produto turístico interage com a base local (espaço físico e atores sociais), levando à geração de atividades conjuntas de empresas relacionadas entre si, com grande poder de criação de aglomerados, e, por conseguinte, também de redes (CUNHA; CUNHA, 2005). E também está diretamente ligado ao meio ambiente que está inserido, causando impactos positivos e negativos, consequências locais e globais.

O conceito de redes vem sendo discutido desde as décadas de 1980 e 1990, o mercado tem dado mais importância à necessidade de eficiência coletiva proporcionada por diferentes tipos de arranjos empresariais. Esses arranjos têm buscado mais efetividade coletiva em diversas formas de atuação, com suas funções voltadas não só para o mercado, mas também para a sua posição dentro das redes de inter-relações. Assim, as redes podem ser entendidas como um modo de organização utilizado para garantir às empresas sustentação e longevidade (JARILLO, 1988).

Nakano (2004) afirma que redes de cooperação têm sido apontadas como uma fonte de inovação, pois dispõem de ambientes onde os conhecimentos podem ser gerados de forma mais eficiente e rápida. O setor turístico tem características destacadas que facilitam a cooperação: a) necessidades de integração da cultura, economia e natureza que resultam em ações e intervenientes que se tornam viáveis a partir de uma atuação sistêmica; b) o poder de atração da região depende do potencial de diferenciação do produto turístico e dos serviços de suporte. (CUNHA; CUNHA, 2005)

Outra especificidade do setor, afirmam Cunha e Cunha (2005), é a sua dependência geográfica. As destinações turísticas são aglomerações territoriais em quase sua totalidade, considerando o fato de as empresas e instituições se localizarem próximas aos atrativos (ANDRIGHI; HOFFMANN, 2008, p. 89). Ainda assim, conclusões empíricas apontam que aglomerações territoriais são tão somente condição facilitadora e não suficiente para impulsionar práticas de cooperação e estabelecimento de redes (CURTIS; HOFFMANN, 2009; COSTA; HOFFMANN, 2014).

Diversas são as nomenclaturas que dizem respeito às aglomerações territoriais, tais como: distritos industriais (DI), clusters, arranjos produtivos locais (APL) e outras. Os distritos industriais (DI) são de origem italiana, especificamente da Terceira Itália, na década de 1980 (COSTA, 2005). São redes de longo prazo desprovidas de relações hierárquicas entre seus integrantes, que são predominantemente de pequeno porte (KNORRINGA; MEYER-STAMER, 1998). Os distritos industriais cons- 
tituem uma entidade socioterritorial, caracterizada pela presença de uma comunidade de pessoas e de uma população de empresas que atuam de forma integrada e independente em um dado espaço geográfico e histórico (COCCO et al., 1999). Posteriormente, na década de 1990, as atenções voltaram-se para os clusters, que se tornaram uma nova maneira de encarar a localização das empresas, a contribuição das universidades para o sucesso delas e como o papel do governo na promoção do local (PORTER, 1998). Cluster não constitui uma organização formalizada de empresas, mas sim, de acordo com o autor, concentrações geográficas atreladas à cadeia de valor que podem impulsionar tanto a cooperação quanto a competição. Por fim, os arranjos produtivos locais (APL), outra denominação bastante utilizada e originada no Brasil, se referem ao tipo de aglomeração geográfica de pequenas e médias empresas, com especialização em determinado produto, sendo ele agrícola, tecnológico ou um serviço (BARBOZA, 2004). Neste contexto, Amato Neto (2007) e Silva e Teixeira (2008) veem nas redes de cooperação, favorecidas pela aglomeração territorial, uma solução para as MPEs alcançarem mais competitividade e estimularem o desenvolvimento local.

Nesse sentido, vale destacar outra característica do setor turístico, de acordo com IBGE (2007), a quantidade de MPEs que compõem o setor é expressiva, aproximando-se de $97 \%$ das empresas de turismo no Brasil. As MPEs têm características peculiares, empresas de menor porte apresentam controle individual do proprietário, nesses tipos de empresas se possui um contato bastante próximo com o mercado consumidor, com isso pode-se flexibilizar às necessidades do cliente, ser mais eficiente e rápido às adaptações em inovações do setor de acordo com seus costumes e tradições da região na qual está inserida (AMATO NETO, 2005). Essas Micro e Pequenas Empresas são tomadas como dinamizadoras de economias locais e como potenciais geradoras de crescimento e desenvolvimento endógeno (AMATO NETO, 2000; COSTA, 2001).

Percebe-se então que as alianças entre empresas de micro e pequeno porte são enfatizados como estratégia de ganho de competitividade e desenvolvimento econômico em níveis locais e regionais, em virtude de vantagens coletivas que os relacionamentos entre elas podem originar (JARILLO, 1988; BESSANT; FRANCIS, 1999; CASAROTTO FILHO; PIRES, 1999).

A ênfase dos estudos atuais ligados à cooperação entre MPE está mais voltada às vertentes da competitividade, seja ela como fenômeno isolado ou como fenômeno sistêmico. No conceito sistêmico, vários fatores afetam a competitividade de cada ator do sistema, neste modelo se engloba a complexidade de interações dinâmicas entre diferentes atores sociais. A complexidade sistêmica pressupõe não só avanços econômicos, mas também desenvolvimento social, surgindo a necessidade de 
avaliar regiões como um todo, não apenas as empresas que a compõem (ESSER et al., 1996). Os autores propõem quatro níveis que se deve levar em consideração ao tratarem planos para aumento da competitividade. Esse níveis são: micro, vem da competitividade das empresas; macro, referente às políticas econômicas; meso, contam com as medidas específicas de governo e ONG; e o quarto e último nível, meta, onde está a capacidade de articular os níveis meso e macro.

De acordo com Meyer-Stamer (2001, p. 21): "o conceito de competitividade sistêmica tem a vantagem de ser suficientemente aberto para abranger os principais pontos fortes e fracos que determinam o potencial de desenvolvimento local ou regional". O modelo sistêmico foi base dos estudos de Dwyer e Kim (2003) que o conceituou em três correntes: a) vantagem comparativa ou perspectiva de competitividade de preços, foco nas características econômicas; b) perspectiva estratégica e gerencial, foco nas características da firma e; c) perspectiva histórica e sociocultural, com foco nos pontos culturais, sociais e políticos da competitividade.

A análise da competitividade de destinos turísticos difere da análise de firmas e indústrias em um ponto relevante dos modelos apresentados. Até o momento, a competitividade esteve essencialmente relacionada à perspectiva do mercado (PORTER, 1989). A competitividade turística foi definida por Hassan (2000) como sendo a capacidade de um destino de manter sua posição no mercado e melhora-los através do tempo. Ao longo do tempo os conceitos sobre o tema vem evoluindo e se agregou novos fundamentos como, sustentabilidade, satisfação e prosperidade econômica da população local (BUHALIS, 2000; RITCHIE; CROUCH, 2000).

No modelo de Dwyer e Kim (2003), propõe-se que para uma destinação ser competitiva não basta ser apenas ecológica e economicamente sustentável, ela também deve ser social, cultural e politicamente sustentável. Assim, fica refletido que a competitividade do destino é um antecedente da economia do bem-estar e da prosperidade da população local. Nessa linha de benefícios das redes de cooperação, o artigo visa destacar ainda mais o turismo como impulsor do desenvolvimento sustentável local. A sustentabilidade é um dos padrões possíveis de desenvolvimento, caracterizado pela eficiência econômica, conservação ambiental e equidade social simultaneamente (BUARQUE, 2004).

Brundtland (1991, p. 53) conceitua o desenvolvimento sustentável como um processo de transformação no qual a exploração dos recursos, a direção dos investimentos, a orientação do desenvolvimento tecnológico e a mudança institucional se harmonizam e reforçam o potencial presente e futuro, a fim de atender às necessidades e aspirações humanas. Esta concepção pressupõe uma estratégia de de- 
senvolvimento que não se baseia em uso predatório da natureza, e é refletida por uma variedade de fatores sociais, econômicos e ambientais interconectados e com dimensões temporais de longo prazo, necessitando de constantes revisões e monitoramento, por se tratar de um processo dinâmico (CALLENS; TYTECA, 1998).

Fundamentalmente, o desenvolvimento sustentável tem como questão inerente a conciliação do desenvolvimento econômico com as necessidades de preservar o ambiente, distribuir riquezas e utilizar os fluxos e fundos naturais a longo prazo (BINSWANGER, 1999). Saarinem (2006, p. 1124) argumenta ainda que, apesar das limitações, a noção de sustentabilidade oferece uma plataforma comum para os atores sociais do turismo "interagirem, negociarem e refletirem sobre os resultados de suas ações frente aos limites de crescimento do meio ambiente".

Assim, tendo em vista que o local estudado é em sua grande área geográfica de proteção ambiental e de grande dependência do setor turístico, vale destacar que o ecoturismo é uma alternativa construtiva, desde que gere empregos e cuide do meio ambiente e da cultura local (CAVALCANTI, 1999). Por fim, Davies (2001, apud THOMAS, 2007) diz que pequenas empresas com raízes na localidade onde operam possuem maior senso de responsabilidade, e por isso, maior tendência ao envolvimento com parcerias em prol do local.

\section{METODOLOGIA}

A pesquisa classifica-se como um estudo de caso (YIN, 2010) descritivo com abordagem qualitativa. Para a coleta dos dados foi utilizado um roteiro semiestruturado, próprio e aberto, para realização de entrevistas com representantes das empresas turísticas de Cavalcante/GO. O roteiro de pesquisa foi dividido em duas partes: a primeira parte com entrevista, que consistiu em um roteiro fechado que busca entender o perfil das empresas da cidade. A segunda parte do roteiro de coleta consistiu em uma entrevista com 12 perguntas abertas que foram trabalhadas no decorrer da entrevista. Foram considerados como representante da empresa, o proprietário, o gestor administrativo, o gerente, e variações do título. Representantes esses que conforme Bardin (1977) sugere-se que sejam representativos, adequados, homogêneos e pertinentes, como foram os participantes do estudo.

A aplicação das entrevistas foi realizada diretamente com os representantes de cada organização em outubro de 2014, totalizando 21 respondentes. Utilizou-se também de observação, tentando levantar o maior número de informações e opiniões, atitudes e comportamentos dos proprietários ou do principal administrador. 
Para os procedimentos de análise, utilizou-se do método de análise de conteúdo de Bardin, que é recomendado para pesquisa qualitativa (TRIVIÑOS, 1987). Esse método é para o estudo das motivações, atitudes, valores, crenças e tendências, e que à simples vista, não se apresentam com devida clareza, e ainda que a análise de conteúdo é um conjunto de técnicas de análise de comunicações, visando obter, por procedimentos sistemáticos e objetivos de descrição do conteúdo das mensagens, indicadores quantitativos ou não, que permitam a inferência de conhecimentos relativos às condições de produção/recepção destas mensagens.

Cavalcante é um município brasileiro do estado de Goiás, que está localizado ao norte da Chapada dos Veadeiros, a cidade foi originada em 1736. Cavalcante é uma das porta de entrada da Chapada dos Veadeiros e cerca de $70 \%$ do parque nacional que protege a região está dentro do município, possui mais de 100 cachoeiras catalogadas, e quase toda sua riqueza ambiental e natural pode ser visitada e apreciada. O município abriga parte da comunidade Kalunga, originalmente formada por descendentes dos primeiros quilombolas. Evidencia-se ainda que em Cavalcante se destaca pelo turismo ecológico, por suas áreas de cerrado, as inúmeras cachoeiras e grutas existentes, como também formações rochosas. Faz parte de uma região com rica biodiversidade e por isso criaram dois parques para proteger este bioma, o Parque Nacional das Emas e o Parque Nacional da Chapada dos Veadeiros, que é parte do lócus do estudo. (PREFEITURA DE CAVALCANTE, 2014).

\section{RESULTADOS E DISCUSSÕES}

\subsection{Atores do setor turístico de Cavalcante/GO}

Empresários, acadêmicos, autoridades e servidores públicos são atores sociais fundamentais para a competitividade de dado setor ou local (COUTINHO, FERRAZ, 1995). O perfil dos atores do setor turístico de Cavalcante/GO foi levantado através de dados coletados na pesquisa de campo mediante instrumento de pesquisa. Participaram da pesquisa 21 organizações, sendo vinte empresas privadas e uma associação. Não foi possível identificar a quantidade exata de empresas formalizadas do setor turístico de Cavalcante, uma vez que não há disponibilidade destas informações.

Os empreendimentos foram classificados em hotéis, pousadas, restaurantes, receptivos turísticos, associações e entretenimento. Observou-se uma predominância de pousadas e restaurantes, treze no total. Mais dois hotéis, cinco receptivos turísticos, uma associação ativa e nenhum entretenimento. A literatura aponta que quanto mais diversificados os atores sociais que participam das relações de rede, mais pode ser favorecida a cooperação entre as empresas e organizações (CASSAROTTO FILHO, PIRES, 1999). 
Atualmente, de acordo com informações advindas da entrevista, há apenas uma associação em atividade na região, a Associação Quilombo Kalunga, que é responsável por representar as comunidades Kalungas. Na percepção dos empresários entrevistados, as associações são de grande importância, o que contrasta com a realidade encontrada. Três dos entrevistados (B, D e O) citaram a Associação Chapada Sustentável e a Associação dos Artesãos como organizações que já foram ativas e importantes para o turismo na região, mas atualmente não estão em funcionamento.

Confirmando o que a literatura aponta acerca do porte das empresas do setor turístico, em Cavalcante, predominam empresas com até 10 funcionários. 0 que, segundo o Sebrae (2014), as caracteriza como MPEs. Foi verificado catorze empresas com até cinco funcionários, seis empresas com até dez funcionários e apenas uma com mais de dez funcionários, sendo a associação.

Apesar de Cavalcante ser uma cidade antiga (fundada em 1736), apenas nas últimas décadas o turismo tornou-se uma atividade economicamente relevante. Isso coaduna com os resultados encontrados, pois a maior parte das empresas possui menos de 10 anos de existência e nenhuma tem mais de 15 anos. Comparando com estudos recentes realizados em Pirenópolis e Alto Paraíso, percebe-se que a realidade de Cavalcante difere do resultado encontrado nessas cidades, nos dois casos os empreendimentos turísticos começaram a aflorar a partir da segunda década de 1980 e desde então a abertura de empresas continua aumentando ano a ano, levando a crer que o turismo nessas regiões ainda está em desenvolvimento (SANTANA et al, 2013). Cenário oposto ao encontrado em Cavalcante, pois, de acordo com alguns entrevistados, muitas empresas turísticas fecharam as portas nos últimos anos, por diversos problemas, tanto de cunho político e gestão pública como por parte da população que tem uma certa resistência ao turismo e empresários que estão pouco entusiasmados em relação às atividades turísticas.

De acordo com dois entrevistados (B e D) cerca de $60 \%$ da população trabalha no setor público ou recebe algum benefício do governo, o que diminui o mercado interno de consumo, reforçando o papel do turismo na economia do município. Para comprovar tal fato, dados disponibilizados pelo Instituto de Pesquisa Econômica Aplicada (IPEA) no site do Ministério do Desenvolvimento Social e Combate à Fome (MDS) mostram que 1250 famílias são beneficiárias do Bolsa Família no município de Cavalcante.

Cavalcante é rodeada por cachoeiras e belezas naturais, de acordo com o entrevistado $P$, quase $100 \%$ da demanda turística recebida busca os atrativos culturais, turismo de natureza e ecoturismo. Mesmo assim, parte dos entrevistados, F, B e $\mathrm{O}$ citou que a cidade não tem um portal de entrada para o parque, o que, na visão da maioria dos representantes, dificulta o turismo e não se dá a devida atenção 
e importância que o município merece. O único portal de entrada para o Parque Nacional da Chapada dos Veadeiros fica em São Jorge, o que rivaliza na atração de turistas com Cavalcante. São Jorge é atualmente, um dos dois polos de turismo de Alto Paraíso (IBGE, 2010), e ficou famosa por sua posição privilegiada onde se localiza a entrada para o Parque Nacional da Chapada dos Veadeiros, que de acordo com Campos e Valente (2010), foi quando houve a inauguração do parque, na década de 1960, que o turismo passou a se desenvolver até se tornar o principal gerador de renda da região.

Identificou-se que a maioria dos proprietários possui escolaridade maior que a da população nativa. Pode-se confirmar esse dado, pois o Censo de 2010 apresenta que $33,5 \%$ da população de Cavalcante ainda é analfabeta. O questionário mostrou que nove tem segundo grau, nove tem terceiro grau, 2 representantes tem o primeiro grau e apenas um com pós-graduação. $O$ fato de a maior parte dos empresários não ser nativo da região também pode contribuir para esse fenômeno. De acordo com alguns entrevistados, $B$ e $D$, e dados encontrados no site do IBGE, referente a 2010, o IDH da cidade é o pior da região de Goiás, com 0,584, enquanto no Brasil o IDH é de 0,727. E para efeito de comparação com outras cidades da mesma região, tem-se Alto Paraíso e Pirenópolis, com o IDH de 0.713 e 0,693, respectivamente.

O estudo também identificou o perfil de gestão das organizações turísticas, onde seis das empresas possuem uma administração mista (família e funcionários), cinco possuem uma gestão profissional e dez das empresas possuem gestão familiar. É importante destacar que as empresas classificadas como profissionais são de pessoas que vieram de outras regiões do país, e têm uma visão empreendedora e mais experiências em negócios. Foi possível observar que estas empresas possuem infraestrutura mais requintada e se posicionam em um patamar de maior sofisticação do que as demais. Por fim, de vinte organizações privadas, quinze afirmaram que aumentam em pelo menos um funcionário na alta temporada.

\subsection{Cooperação e Ações Cooperativas}

Na literatura, a cooperação entre empresas normalmente envolve três aspectos: relacionamento com base em confiança, troca de informações e as ações coletivas reais (KNORRINGA, MEYER-STAMER, 1998). Neste contexto, verificou-se que existe pouca ou nenhuma confiança entre as organizações estudadas, e que há poucas conversas sobre o próprio negócio ou troca de informações sobre o mercado e clientes. O representante da empresa B afirmou que "já esteve pior, (mas que) hoje está tendo um pouco mais de conscientização (por parte dos empresários) de que 
isso precisa mudar...". Já o representante da empresa L indicou que essa conversa existe com os amigos e colegas, mas não é uma regra para todos. Essa opinião é corroborada por outros entrevistados. Por outro lado, o representante da empresa N queixou-se de que "aqui (Cavalcante) é um pouco cada um por si.", demonstrando uma opinião negativa sobre as relações de confiança na região.

Ainda assim, a maioria dos entrevistados afirmou que não existe concorrência ou que as empresas não se enxergam como concorrentes, corroborando, assim, o estudo feito por Werger e Padula (2012) que diz que mesmo havendo inexistência de rivalidade o estabelecimento espontâneo e eficiente de cooperação não está assegurado. Esta situação fica explícita em Cavalcante já que não foram identificadas relações formais de cooperação ou realização de ações coletivas, ainda que não seja revelada uma forte noção de concorrência.

Mesmo nesse cenário, quando perguntados sobre a importância da cooperação, todos afirmaram que a cooperação tem grande importância para o turismo e, de maneira geral, prefeririam resolver os problemas em conjunto ou aceitariam mais ações coletivas. Essas dificuldades de estabelecer relações coletivas aparecem na literatura diversas vezes, Rodrigues (1998) destaca que alguns fatores impedem as alianças estratégicas: o bairrismo, receio de perda de poder, o personalismo, a competição e a falta de percepção do ambiente competitivo por líderes empresariais. Evidencia-se na fala de alguns entrevistados: Empresa D - "Trabalhar em conjunto é imprescindível."; Empresa I - "Já traz muitos benefícios, o pouco que tem já é muito bom." ; Empresa M - "Melhora a competitividade".

A indicação de outro estabelecimento foi a ação de cooperação mais recorrente na fala dos entrevistados, alguns afirmaram que isso é algo que traz confiança para o cliente em relação ao turismo da cidade, isto é, ao indicar um estabelecimento concorrente ou de outro segmento do turismo, o cliente percebe que a empresa não está interessada apenas no seu benefício, mas que se preocupa com as necessidades do seu cliente. $O$ representante da empresa $P$, por exemplo, afirmou que "não tem cooperação, mas tem muita indicação".

Quando questionados se existe uma inclinação a fazer mais ações coletivas, percebeu-se que de forma geral os entrevistados estavam abertos para esse tipo de relação. Fato expresso pela entrevistada da empresa $\mathrm{G}$ que citou como exemplo as compras e treinamento de funcionários como possíveis ações conjuntas que trariam benefícios para empresa.

Os canais de comunicação entre as organizações consistem em uma característica das redes que pode gerar vantagem competitiva (POWELL, 1990). Nesse sentido, 
percebeu-se que os canais de comunicação de Cavalcante são pouco utilizados, não existe interação ou reuniões para discutir estratégias para o desenvolvimento do turismo. Uma entrevistada, $\mathrm{K}$, citou que "não temos reuniões há algum tempo para discutir essas coisas...". Muitos dos entrevistados citaram que o maior impulsor desse tipo de reunião é o Sebrae, que algumas vezes promoveu programas de turismo/ treinamentos, palestras e reuniões que ajudaram na propagação do turismo entre os empresários da região. Porém, são ações isoladas e sem periodicidade definida caracterizam uma atitude passiva por parte dos empresários em relação a esse tipo de iniciativa, ainda que percebam valor em sua realização

A cidade conta com um Centro de Atendimento ao Turismo (CAT), que por muitas vezes se tentou contato, mas sem sucesso. Conta também com uma Secretaria de Turismo que em nenhum dia de pesquisa estava aberta e com o Conselho de Turismo (CONTUR) que também está desativado. Esse cenário reforça a opinião de todos os empresários entrevistados, que citaram o não funcionamento desses órgãos como sendo um grande atraso para o desenvolvimento do turismo na cidade. Tendo em vista que são órgãos de grande importância para o estabelecimento de comunicação entre a cidade e as empresas, assim como entre os representantes de todas as empresas.

O estudo de Santana et al. (2013) apresentou um cenário diferente, mostrando a importância dos órgãos públicos para o desenvolvimento do turismo. $O$ estudo feito em Pirenópolis contrasta com a realidade de Cavalcante, mostrou um alto grau de centralidade dos órgãos de administração pública, isso indica uma baixa articulação entre as empresas privadas da região, dependendo, em grande parte, do setor público para implantação de ações conjuntas. No entanto, segundo os autores da pesquisa, privilégios de uma posição central dentro da rede, como a da Secretaria de Turismo, vêm acompanhados de maior responsabilidade com o todo. (SANTANA et al., 2013). Por isso, o fato dos órgãos públicos não exercerem seu papel plenamente por si só já seria um prejuízo para a cidade, pois isso causa um atraso para as atividades empresariais. Visto que, atores centrais são responsáveis por colocar boa parte dos atores em contato com os demais.

\subsection{Cooperação para o desenvolvimento sustentável da localidade}

A ação em conjunto de pequenas empresas pode ir além do seu próprio crescimento, estendendo-se ao desenvolvimento local através da geração de empregos e receita para o município (SOUZA; BACIC, 2002). Quando perguntados sobre o impacto da cooperação para o desenvolvimento da cidade, grande parte dos entrevistados 
afirmou que acredita no desenvolvimento local em consequência da cooperação entre as empresas. Para exemplificar esse fato, foi citado por uma entrevistada G que "com certeza, através da cooperação há desenvolvimento". E outro, da empresa $M$ citou que "ações (de cooperação) trazem desenvolvimento local, o que atrai o turista, e quanto mais turistas mais benefícios a cidade recebe". Em contraponto, uma minoria acredita que não há relação direta do envolvimento entre as empresas e o crescimento local, conforme relato da entrevistada da empresa $\mathrm{N}$ "ações conjuntas não trazem impacto para a cidade".

Na percepção dos entrevistados, para haver desenvolvimento teria que haver mais incentivo do governo. Para eles, as políticas públicas são falhas, falta manutenção, acompanhamento e melhoria na infraestrutura, são afirmações feitas pelas empresas $\mathrm{D}, \mathrm{H}, \mathrm{P}$ e I. Outro representante da empresa F, também afirmou que uma das causas para o turismo não funcionar é a falta de gestão pública para divulgar o local. Por outro lado, uma entrevistada acredita que "depender do governo somente atrasa o turismo da região, que na verdade deveria existir mais proatividade". Compartilhando com a opinião da representante da empresa N que também acredita que "o povo sempre espera muito da prefeitura". Essa opinião corrobora com o estudo de Costa e Miranda Junior (2013), que constatou que dentre as dificuldades de se estabelecer cooperação entre os hotéis de Brasília, a ausência de suporte de entidades governamentais como a explicação mais frequente entre os entrevistados.

Foi citada também uma forte resistência da população nativa ao acolher o turismo como uma fonte de desenvolvimento econômico para a cidade. Um entrevistado (empresa O) cita que "há um grande conservadorismo por parte da população local", pois eles avaliam o turismo como uma atividade predatória para a natureza local e para sociedade nativa como um todo. $O$ fato de as empresas do setor turístico serem gerenciadas majoritariamente por profissionais que vieram de fora de Cavalcante contribui para essa percepção negativa por parte da população. Além disso, há um temor na população nativa de que os "estrangeiros", que já dominaram o comércio, também os exclua das melhores oportunidades de emprego e descaracterize a cultura local, que tem valor histórico. Isso ficou claro na entrevista com o representante da associação $U$, que é composta unicamente por representantes Kalungas (nativos da região).

Essa resistência da população, de acordo com alguns entrevistados, não se justifica, pois, segundo o entrevistado B "temos $96 \%$ de área preservada" e foi possível identificar nas entrevistas que as ações de preservação são valorizadas pelos empresários. Muitas ações em prol da preservação do meio ambiente foram citadas 
por todos os participantes das entrevistas. Segundo eles, essas ações sempre aconteceram na história de Cavalcante, destacando-se o Mutirão de lixo e a Campanha contra o fogo, mas muitos relataram que atualmente elas não ocorrem com a mesma frequência.

Esse é um fato importante, pois o turismo na região é predominantemente de aventura e natureza, o que depende da boa conservação do meio ambiente. Mas, segundo o entrevistado $D$ há um grau de conscientização maior nos turistas do que nos próprios empresários. Houve ações na tentativa da abertura de um Jardim Botânico na cidade, e mais ações e reuniões para abrir um portal para o Parque Nacional da Chapada dos Veadeiros. Mas também são iniciativas que não obtiveram respostas, foram embargadas e estão paralisadas.

Por fim, o último tópico abordado na entrevista, foi sobre os planos e metas das empresas para manter ou aumentar a competitividade individual e local. Das vinte empresas privadas, sete tem o objetivo de melhorar ou aumentar o empreendimento visando mais competitividade, nove empresas pensam em manter a organização como está, mantendo a qualidade já alcançada e quatro empresas pensam em vender ou fechar o empreendimento. Essa visão de futuro é interessante de ser apurada, tendo em vista que o conceito de sustentabilidade apenas faz sentido em uma visão de longo prazo (COSTA, 2013).

\section{CONCLUSÕES}

O artigo teve como objetivo verificar, na ótica dos atores envolvidos, a existência de cooperação entre as organizações de Cavalcante (GO) e suas eventuais contribuições para a competitividade e a sustentabilidade do destino turístico. Para tanto, foi necessário descrever os atores do setor turístico de Cavalcante/GO; verificar a existência de ações cooperativas entre as organizações do setor turístico de Cavalcante/ GO; identificar os resultados das ações de cooperação na percepção dos atores envolvidos e, por fim, verificar as ações de cooperação favoráveis ao desenvolvimento do destino estudado.

Na revisão teórica, abordou-se a temática das redes de cooperação, repassando conceitos e autores da área e foi feita uma diferenciação das nomenclaturas utilizadas na literatura para redes. Também se revisou sobre a cooperação em micro e pequenas empresas, evidenciando suas peculiaridades e mostrando seus lados positivos e vantagens para o relacionamento de redes, principalmente no turismo. Em seguida foi revisado o desenvolvimento local, tentando entender os principais 
conceitos do assunto e definindo os impactos positivos e negativos locais advindos das atividades cooperativas no turismo de uma região.

Percebeu-se que as parcerias entre empresas ou associações da cidade revelaram-se simplistas e informais e dentre as possíveis ações de cooperação, a indicação de outro estabelecimento quando o do respondente está sem vaga ou quando não estava de acordo com as reais necessidades do cliente foi a que obteve unanimidade, indicando indícios de conversa entre eles, e uma prática aparentemente consolidada entre os empreendimentos. Práticas mais complexas, como a realização de compras e contratação de serviços ou treinamentos em conjunto, ou a promoção do turismo por meio de ações coletivas constituem uma realidade ainda distante para as empresas de Cavalcante. Ainda assim, os entrevistados parecem compreender as vantagens que podem ser obtidas com as redes de cooperação. Em geral, os representantes se disseram inclinados a cooperar, o que de fato contrasta com a realidade. Por isso, vale ressaltar o que diz respeito às dificuldades em cooperar, um motivo bastante apontado foi a falta de interesse e compromisso dos empresários da cidade e envolvidos do setor turístico.

Notou-se também que as vantagens competitivas para a cidade e para as empresas do setor advindas das ações cooperativas são bem compreendidas pelos atores envolvidos, há uma consciência unânime dos benefícios trazidos em prol do desenvolvimento sustentável local por meio do comportamento de redes. No entanto, a prática difere do pensamento geral, pois as ações de preservação não estão acontecendo com periodicidade, e os benefícios não foram expressamente apresentados.

Portanto, de acordo com a literatura e os dados identificados no roteiro, conclui-se que em Cavalcante as redes de cooperação entre os empresários do setor turístico ainda são incipientes, assim como as estratégias do estado e da Prefeitura para com as empresas do setor. Assim, a cidade pode ser caracterizada por baixa taxa de cooperação e competição, tendendo a acordos informais e oferecimento de barreiras a novos entrantes no turismo local.

A pesquisa encontrou algumas limitações, como a dificuldade em se obter dados oficiais sobre as empresas turísticas da cidade, poucos estudos acadêmicos sobre o tema, especialmente com foco nos possíveis impactos que as redes podem ter no desenvolvimento sustentável de qualquer região, tendo em vista que a maior parte das publicações aborda a relação entre cooperação e competitividade. São sugeridas, então, abordagens complementares, bem como outras pesquisas qualitativas com maior profundidade. 


\section{REFERÊNCIAS}

AMATO NETO, J. Redes de cooperação produtiva e cluster regionais: oportunidades para pequenas e médias empresas. São Paulo: Atlas, 2000. AMATO NETO, J. Redes dinâmicas de cooperação e organizações virtuais. Redes entre organizações. p. 68-93. São Paulo: Atlas, 2005.

AMATO NETO, J.; SANTOS, I. C. Gestão do conhecimento: origem, conceitos e aplicações nas organizações. In: CHAMON, E. M. Q. O. (org.). Gestão e comportamento humano nas organizações. Rio de Janeiro: Brasport, 2007.

ANDRIGHI, F.; HOFFMANN, V. E. Aglomeração Territorial no Turismo: Uma Avaliação dos Atores Sociais na Destinação Turística de Urubici/SC. Revista Cultura de Turismo, ano 02, n² 2, jul. 2008.

BARBOZA, L. C. Arranjos Produtivos Locais: uma estratégia de política industrial. In CAPORALI, R.; VOLKER, P. Metodologia de Desenvolvimento de Arranjos Produtivos Locais: projeto PROMOS - SEBRAE - BID versão 2.0. Brasília, Sebrae, 2004.

BARDIN, L. Análise de Conteúdo. Lisboa, Portugal: Edições 70, 1977. BESSANT, J.; FRANCIS, D. Using Learning Networks to Help Manufacturing Competitiveness. In Technovation, v.19, n., 1999.

BUHALIS, D. Marketing the competitive destination of the future. In Tourism Management, v. 21, n., 2000.

BRUNDTLAND, G. R. Nosso futuro comum: comissão mundial sobre meio ambiente e desenvolvimento. 2a ed. Rio de Janeiro: Fundação Getúlio Vargas, 1991. BUARQUE, S. C. Construindo o desenvolvimento local sustentável: metodologia de planejamento. 2a ed. Rio de Janeiro: Garamond, 2004.

BINSWANGER, H. C. Fazendo sustentabilidade funcionar. In: CAVALCANTI, C. O. (org.). Meio Ambiente, Desenvolvimento Sustentável e Políticas Públicas, 1999 CALLENS, I.; TYTECA, D. Towards indicators of sustainable development for firms: a productive efficiency perspective. Ecological Economics, v. 28, p. 41-53, 1998.

CAMPOS, J. I.; VALENTE, A. L. E. F. A construção do mercado para o café em Alto Paraíso de Goiás. RESR - Revista de Economia e Sociologia Rual, v. 48, n. 1, p. 23-40, jan./mar., 2010.

CAVALCANTI, C. Políticas de Governo para o Desenvolvimento Sustentável. In Meio Ambiente, Desenvolvimento Sustentável e Políticas Públicas, v., n., 1999.

CASAROTTO FILHO, N.; PIRES, L. H. Redes de pequenas e médias empresas e o desenvolvimento local. São Paulo: Atlas, 1999. 
COCCO, G. A nova qualidade do trabalho na era da informação. In: LASTRES, Helena, M. M.; ALBAGLI, S. (orgs). Informação e Globalização na Era do Conhecimento. Rio de Janeiro: Campus, 1999.

COSTA, H. A. Destinos do turismo: percursos para a sustentabilidade. Rio de Janeiro: FGV, 2013.

COSTA, H. A.; HOFFMANN, Valmir Emil. A cooperação entre micro e pequenas empresas aglomeradas como recurso estratégico em destinos turísticos. In: Costa, CarIos; Brandão, FElipa; Costa, Rui; Breda, Zelia. (Org.). Produtos e Competitividade do Turismo na Lusofonia: vol II. 1ed.Lisboa: Escolar Editora, 2014, v. II, p. 39-50

COSTA, H. A,; MIRANDA, N. Dificuldades para a cooperação entre hotéis sediados em Brasília, Distrito Federal. In: III Congreso Internacional 'Ciencias tecnologias y culturas. Dialogos entre las disciplinas del conocimiento, 2013, Santiago.

COSTA, H. A. Contribuição das redes de pequenas e médias empresas para a competitividade de destinações turísticas: estudo comparativo entre Laguna e São Francisco do Sul-SC. Dissertação de Mestrado, Departamento de Turismo e Hotelaria, Universidade do Vale do Itajaí, Balneário Camboriú, SC, Brasil, 2005.

COSTA, M. T. As pequenas e médias empresas no desenvolvimento local: conceitos e experiências. In: GUIMARÃES, N. A.; MARTIN, S.; Orgs. Trabalho e sociedade competitividade e desenvolvimento: atores e instituições locais. São Paulo: Editora Senac, 2001.

COUTINHO, L.; FERRAZ, J. C. Estudo da Competitividade da Indústria Brasileira. 3ạ ed. Campinas, SP: Papirus, 1995.

CUNHA, S. K.; CUNHA, J. C. Tourism cluster competitiveness and sustainability: proposal for a systemic model to measure the impact of tourism on local development, BAR - Brazilian Administration Review, vol. 2, n. 2, p. 47-62, jul./dec. 2005.

CURTIS, L.; HOFFMANN, V. E. Relacionamentos Interorganizacionais, em Contexto de Aglomeração Territorial: um estudo no setor hoteleiro das destinações turísticas de Gramado e Canela (RS). XXXIII Encontro da Anpad. Rio de Janeiro 2009.

DENICOLAI, S.; CIOCCRELLI, G.; ZUCHELLA, A.; Resource-based local development and networked core-competencies for tourism excellence. Tourism Management, vol. 31, p. 260-266, 2010.

DWYER, L.; KIM, C. Destination competitiveness: determinants and indicators, Current Issues in Tourism, vol. 6, n. 5, 2003. 
ESSER, K.; HILLEBRAND, W.; MESSNER, D.; MEYER-STAMER, J. Competitividad sistémica: Nuevo desafío a las empresas y a la política. Revista de la CEPAL, n. 59, 1996. HÅKANSSON, H.; SNEHOTA, I. No business is an island: the network concept of business strategy. Scandinavian Journal of Management, v. 5, $n^{\circ}$ 3, p. 187-200, 1989. HASSAN, S. S. Determinants of market competitiveness in environmentally sustainable tourism industry. In: Journal of Tourism Research. [S.I.], v. 38, p. 230-245, feb. 2000.

INSTITUTO BRASILEIRO DE GEOGRAFIA E ESTATÍSTICA, IBGE. Economia do Turismo: análise das atividades características do turismo 2003, Rio de Janeiro: 2007.

INSTITUTO BRASILEIRO DE GEOGRAFIA E ESTATÍSTICA. Censo Populacional. Brasília: IBGE, 2010.

JARILLO, J. C. On Strategic Networks. Strategic Management Journal, vol. 9, p. 31-41, 1988. JUNIOR, N. S. M. Dificuldades para estabelecer ações de cooperação: estudo dos hóteis em Brasília. Monografia de graduação. Departamento de Administração da Universidade de Brasília, 2013.

KNORRINGA, P.; MEYER-STAMER, J. New dimensions in local enterprise cooperation and development: from clusters to industrial districts. InUNCTAD (org.). New approaches to science and technology co-operation and capacity building. (ATAS Bulletin XI). New York, Geneve: United Nations, nov, 1998.

MALHOTRA, N. Pesquisa de Marketing: uma orientação aplicada. Porto Alegre: Bookman, 2011.

MEYER-STAMER, J. Estratégias de Desenvolvimento Local e Regional: Clusters, Política de Localização e Competitividade Sistêmica. Policy Paper, n. 28, setembro, 2001. MINISTÉRIO DO DESENVOLVIMENTO SOCIAL E COMBATE À FOME. Pesquisa bolsa família, 2014. Disponível em: http://www.mds.gov.br/saladeimprensa/noticias/2014/ novembro/bolsa-familia-atende-mais-de-14-milhoes-de-familias-em-novembro. Acesso em 17 de novembro de 2014.

NAKANO. "A economia solidária no Estado de São Paulo». In: L.I. Gaiger (org.). Sentidos e experiências da economia solidária no Brasil. Porto Alegre: Editora da UFRGS, 139-171, 2004.

PORTER, M. E. Vantagem competitiva: Criando e sustentando um desempenho superior. Rio de Janeiro: Campus, 1989. . Clusters and teh New Economics of Competition. In Harvard Business Review, nov/dec. 1998. 
POWELL, W. W. Neither market nor hierarchy: Network forms of organization. Research in organizational behavior, vol.12, p.116-145, 1990.

PREFEITURA MUNICIPAL DE CAVALCANTE. História da Cidade, 2014. Disponível em:http://www.cavalcante.go.gov.br/historia-da-cidade. Acesso em 13 de setembro de 2014.

RITCHIE J. R. B., CROUCH G. I. The competitive destination: A sustainability perspective. Tourism Management, v.21, p.1-7, 2000.

RODRIGUES, R. Aprender a surfar. Revista Agroanalysis. São Paulo, v. 18, n. 12, dez, 1998.

SAARINEN, J. Traditions of sustainability in tourism studies. In Annais of Tourism Research, v. 33, n. 4, p. 1121-1140, 2006.

SANTANA, L.; HOFFMANN, V. E.; COSTA, H. A. Cooperação como fonte de Competitividade: Um Estudo Comparativo entre os Destinos Turísticos de Alto Paraíso e Pirenópolis (GO). In: 3 Es - Anpad, 2013, Bento Gonçalves. Anais do 3Es, 2013.

SEBRAE. Consulta Micro e Pequenas Empresas Nacionais. Disponível em:http:// www.sebrae.com.br/sites/PortalSebrae/. Acesso em 30 outubro de 2014.

SILVA, A. J. H.; TEIXEIRA, R. M. Em busca de uma abordagem integradora para analisar vantagem competitiva no setor hoteleiro. Revista Brasileira de Gestão e Desenvolvimento Regional, p. 172-192, 2008.

SOUZA, M. C. A. F.; BACIC, M. J. Restrições ao desenvolvimento de alianças e práticas inovadoras em arranjos produtivos locais: o caso do setor de plásticos do $A B C$ Paulista. In: Anais do ENANPAD. Salvador: setembro de 2002.

SOUZA, S. M. A.; CÂNDIDO, G. A. Relações entre as formas de arranjos produtivos com a competitividade e o desenvolvimento local sustentável. Revista Gestão Industrial, vol.05, n.01, p.161-187, 2009.

THOMAS, R. Tourism partnerships and small firms: power, participation and partition. In Entrepreneurship and Innovation, v. 8, n. 1, 2007.

TRIVIÑOS, A.N.S. Introdução à pesquisa em ciências sociais: a pesquisa qualitativa em educação. São Paulo, Atlas, 1987.

WEGNER, D.; PÁDULA, A. D. Quando a cooperação falha: um estudo de caso sobre o fracasso de uma rede interorganizacional. Revista de Administração Mackenzie, v. 13, p. 145-171, 2012.

YIN, R. K. Estudo de caso: planejamento e métodos. Porto Alegre: Bookman, 2010. 